\title{
A not-so-sweet diagnosis: secondary biliary cirrhosis from a "lollipop" stone
}

\author{
Mark A. Gromski, MD, Raj Vuppalanchi, MD, Stuart Sherman, MD, Evan L. Fogel, MD, MSc \\ Division of Gastroenterology and Hepatology, Department of Medicine, Indiana University \\ School of Medicine, Indianapolis, Indiana, USA
}

A 36-year-old man with intermittent pruritus for 2 years was referred for management of ascending cholangitis. He had undergone cholecystectomy 13 years previously, complicated by bile duct injury requiring endoscopic stent placement. He did not recall instructions for a repeat ERCP and was subsequently lost to follow-up.

Blood work at presentation revealed a white blood cell count of $17.6 \mathrm{kcells} / \mathrm{mm}^{3}$, total bilirubin $5.6 \mathrm{mg} / \mathrm{dL}$, alkaline phosphatase $329 \mathrm{U} / \mathrm{L}$, aspartate aminotransferase $79 \mathrm{U} / \mathrm{L}$, and alanine aminotransferase $53 \mathrm{U} / \mathrm{L}$. A CT scan revealed biliary dilation with the stent in place and esophageal varices. ERCP at our institution identified varices, the stent embedded within a 5-cm "lollipop" stone (A), and pus within the bile duct. The stent fractured upon attempts at removal, and a new stent was placed to ensure drainage.

A transjugular liver biopsy sample with portal pressure measurement confirmed the diagnosis of cirrhosis with portal hypertension. A workup for competing etiologies of cirrhosis was negative. A diagnosis of secondary biliary cirrhosis from chronic cholestasis was made. He subsequently underwent several ERCPs with electrohydraulic lithotripsy for destruction and/or removal of the 5-cm stone (B and $\mathbf{C}$ ) and the 13-year-old stent, a proximal 2-cm stone, and serial

This is the author's manuscript of the article published in final edited form as:

Gromski, M. A., Vuppalanchi, R., Sherman, S., \& Fogel, E. L. (2016). A not-so-sweet diagnosis: secondary biliary cirrhosis from a "lollipop" stone. Gastrointestinal Endoscopy, 84(1), 198-200. http://doi.org/10.1016/j.gie.2015.12.008 
stenting of a biliary stricture. Currently, he is asymptomatic with normal liver tests, with all stents removed (D).

\section{Disclosure}

All authors disclosed no financial relationships relevant to this publication.

\section{Commentary}

Last year a middle-aged man was referred to the Humanitas Research Hospital endoscopy unit for cholangitis. His medical history was negative. The patient only vaguely remembered having had "an endoscopy,” for reasons he could not recall, 10 years earlier. Unfortunately, no medical records pertinent to that episode of care were available to ascertain the type of and indication for the endoscopic procedure. Imaging performed in the emergency department revealed mild dilation of the common bile duct and, much to everybody's surprise, the presence of a biliary stent. The plastic stent, which clearly had been there for a very long time, was successfully removed endoscopically. It seemed incredible that it could somehow be "forgotten" and stayed in place for such a long time. We had seen it all!

That is, until Gromski and colleagues presented this Focal Point report. Unlike our patient, the "forgotten" retained stent in this case served as the nidus for the formation of a large biliary stone, which the authors very colorfully nicknamed “lollipop stone,” resulting in significant hepatic damage. Secondary biliary cirrhosis after iatrogenic common bile duct injuries has been previously described but never from lithiasis formed in the context of a longterm retained biliary stent. This case is unparalleled in the literature.

Why was the stent left in place for such a long time? Was it because the surgeons did not clearly explain to the patient what to do in follow-up? Was it because the patient underestimated 
or ignored instructions? A little bit of both? Whatever the reason, we believe this case represents a fundamental reminder of the necessity of strict follow-up in endoscopy as well as of the great value of clear doctor-patient communication. 
Figure

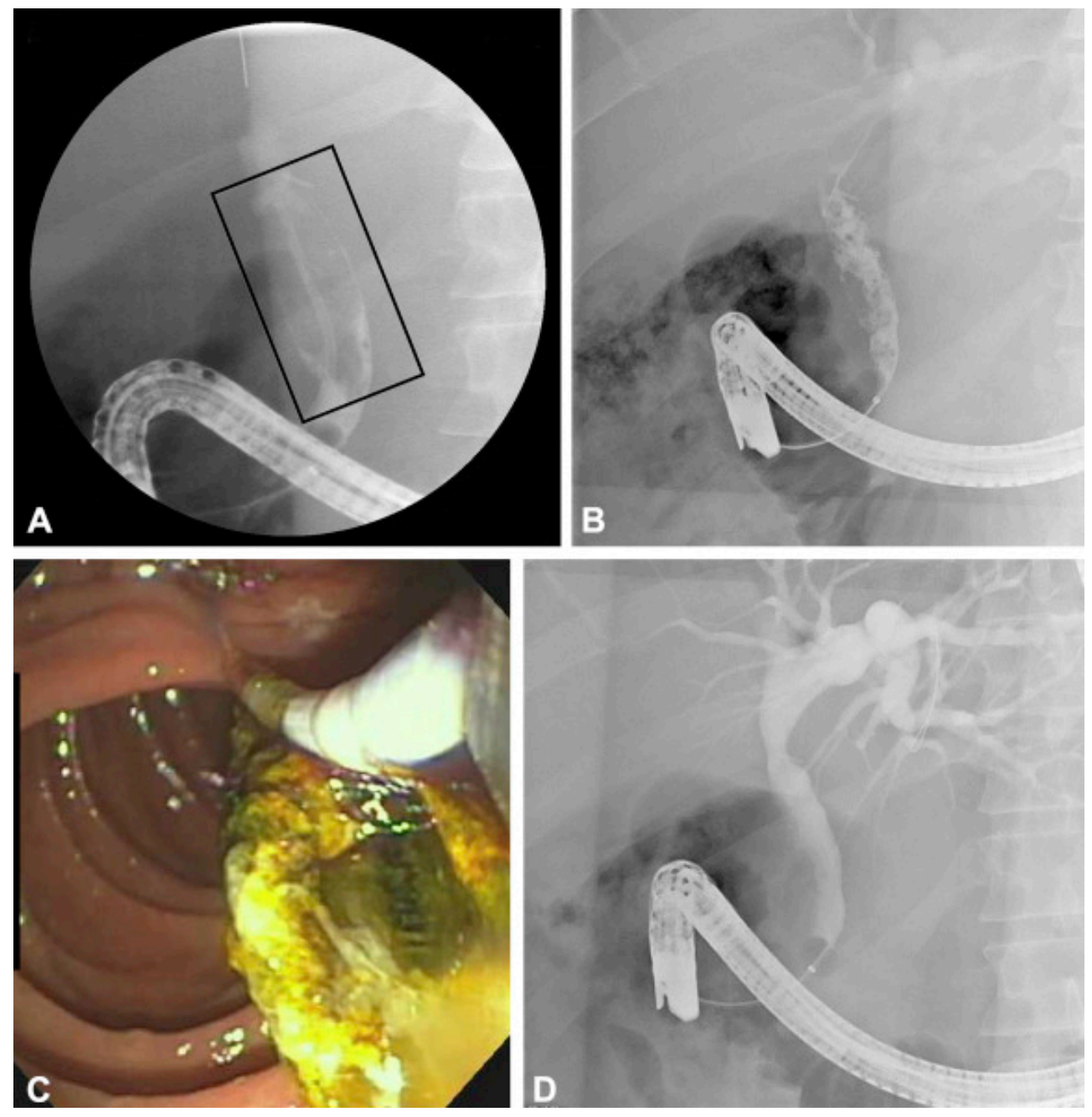

